\title{
ANALISIS EVALUASI SUMBER DAYA MANUSIA DAN KIE PADA PELAKSANAAN MANAJEMEN LAKTASI DI PUSKESMAS
}

\author{
Vittria Meilinda \\ Program Studi Kebidanan Universitas Fort De Kock Bukittinggi \\ Email: vittriameilinda@fdk.ac.id
}

Submitted : 28-01-2020, Reviewer:16-02-2020, Accepted: 17-02-2020

\begin{abstract}
ABSTRAK
Manajemen laktasi bagi ibu hamil didasarkan pada konsekuensi proses pertumbuhan dan perkembangan bayi sejak dalam kandungan sampai saat dilahirkan dan pada masa emas kehidupan awalnya. Dalam pelaksanaannya terutama dimulai pada masa kehamilan segera setelah persalinan dan pada masa menyusui selanjutnya.

Tujuan penelitian ini untuk mengeksplorasi, mendeskripsikan, menginterpretasikan dan mengevaluasi sumber daya manusia (SDM) dan KIE pada pelaksanaan manajemen laktasi di Puskesmas.

Metode penelitian kualitatif, desain penelitian survey deskriptif. Penelitian dilakukan di wilayah kerja Dinas Kesehatan Kota Padang. Informan terdiri dari Bagian Gizi Dinas Kesehatan Kota Padang, Kepala Puskesmas, dan Pelaksana Kesehatan Ibu, Tenaga Gizi, dan Pengguna Pelayanan, pemilihan informan secara purposive sampling. Pengumpulan data dilakukan melalui wawancara mendalam serta observasi pada saat dilapangan dipaparkan melalui matrik Triangulasi.

Hasil penelitian dari evaluasi pelaksanaan manajemen laktasi di Puskesmas Kota Padang sudah dilakukan dengan maksimal dan sesuai dengan SOP tetapi masih terdapat kendala seperti kesibukan ibu bekerja, kesibukan petugas kesehatan, pengetahuan ibu, dukungan keluarga dan sikap maka pelaksanaan manajemen laktasi dari masa kehamilan, segera setelah lahir hingga masa nifas belum mencapai target. Sebagian besar pengguna pelayanan mengungkapkan bahwa pada saat ANC penjelasan KIE mengenai ASI belum sepenuhnya mereka dapatkan, tetapi pelaksanaan IMD dan ASI Eksklusif sudah dilakukan dengan baik.

Disimpulkan bahwa program manajemen laktasi ini perlu dimaksimalkan, terutama kunjungan antenatal yang berkualitas, penyampaian KIE ASI.

Kata kunci: Manajemen Laktasi, IMD, ASI Eksklusif
\end{abstract}




\section{PENDAHULUAN}

Dalam rangka menurunkan angka kesakitan dan kematian anak, United Nation Childrens Fund (UNICEF) dan World Health Organization (WHO) merekomendasikan sebaiknya anak hanya diberi air susu ibu (ASI) selama paling sedikit enam bulan. Makanan padat seharusnya diberikan sesudah anak berumur 6 bulan, dan pemberian ASI dilanjutkan sampai anak berumur dua tahun (WHO, 2013:p.3). Pada tahun 2003, pemerintah Indonesia mengubah rekomendasi lamanya pemberian ASI eksklusif dari 4 bulan menjadi 6 bulan. (Infodatin, 2014: p.1)

Upaya kesehatan anak antara lain diharapkan mampu menurunkan angka kematian anak. Indikator angka kematian yang berhubungan dengan anak yakni Angka Kematian Neonatal (AKN), Angka Kematian Bayi (AKB), dan Angka Kematian Balita (AKABA). Perhatian terhadap upaya penurunan angka kematian neonatal (0-28 hari) menjadi penting karena karena kematian neonatal memberi kontribusi terhadap 59\% kematian bayi. Berdasarkan hasil Survei Demografi dan Kesehatan Indonesia (SDKI) tahun 2012, Angka Kematian Neonatus (AKN) pada tahun 2012 sebesar 19 per 1.000 kelahiran hidup. Angka ini sama dengan AKN berdasarkan SDKI tahun 2007 dan hanya menurun 1 poin dibanding SDKI tahun 2002-2003 yaitu 20 per 1.000 kelahiran hidup. (Profil Kesehatan Indonesia 2015, p.125)

Pada sektor kesehatan Sustainable Development Goals (SDGs) di Indonesia salah satunya menjamin kehidupan yang sehat dan mendorong kesejahteraan bagi semua orang di segala usia. Sasaran yang akan ditempuh diantaranya mengurangi Angka Kematian Ibu (AKI) hingga dibawah 70 per 100.000 kelahiran hidup, mengakhiri kematian bayi dan balita yang dapat dicegah, dengan menurunkan Angka Kematian Neonatal hingga 12 per 1.000 kelahiran hidup dan Angka Kematian Balita 25 per 1.000 kelahiran hidup.(ICTOH, 2017)

Hasil penetian dari Edmond, dkk (2006,p.1) yang dilakukan di Ghana pada bulan juli 2003 sampai Juni 2004, menghubungkan antara waktu dilakukannya tindakan inisiasi menyusui serta pola pemberian ASI dengan kejadian kematian bayi. Ternyata, dari 10.947 bayi yang dilahirkan dalam keadaan sehat dan diikuti perkembangannya selama sebulan, ternyata 
bayi yang tertunda sampai 24 jam lebih baru dilakukan kontak dengan ibunya, mengalami kematian 2,5 kali lebih banyak dibandingkan dengan bayi yang dilakukan inisiasi dini. Kesimpulannya: 22\% kematian bayi yang baru lahir, yaitu kematian yang terjadi dalam satu bulan pertama, dapat dicegah bila bayi disusui oleh ibunya dalam satu jam pertama kelahiran. (Anik Maryunani,2012 : p.69)

Akhir-akhir ini, di bidang Kesehatan Ibu dan Anak semakin digalakkan tentang penatalaksanaan Inisiasi Menyusu Dini, ASI Eksklusif dan Manajemen Laktasi. Ketiga program ini saling berkaitan satu sama lain. Tatalaksana manjemen laktasi dan inisiasi menyusu dini (IMD) yang optimal dan maksimal sangat mendukung didapatnya Air Susu Ibu (ASI) yang eksklusif. Cakupan ASI eksklusif yang ditargetkan dalam program pembangunan nasional dan strategi nasional adalah 80\%. Oleh karena itu, penting untuk menyampaikan informasi tentang manajemen laktasi dan IMD kepada ibu pada saat antenatal, intranatal, postnatal serta tenaga kesehatan yang dapat melaksanakan tugas sebagai promotor profesional dalam penggunaan ASI (Anik Maryunani,2012 : p.1-2)

Mengacu pada terget rencana strategis program Direktorat Jenderal Bina Gizi dan
Kesehatan Ibu dan Anak tahun 2015-2019 dimana Indikator Pembinaan Gizi Masyarakat khususnya pada bayi usia kurang dari 6 bulan yang mendapat ASI Eksklusif dan bayi baru lahir mendapat Inisiasi Menyusu Dini (IMD) sebesar 44\%, maka secara nasional cakupan pemberian ASI eksklusif pada bayi usia kurang dari enam bulan sebesar 54\% telah mencapai target. Menurut provinsi, kisaran cakupan ASI eksklusif pada bayi umur 0-5 bulan antara 32,3\% (Gorontalo) sampai 79,9\% (Nusa Tenggara Timur). Dari 33 provinsi yang melapor, sebanyak 27 diantaranya (79\%) berhasil target renstra 2017. Dan cakupan pemberian ASI eksklusif di Sumatera Barat mencapai 52,8\% dan berada pada posisi ke 15 dari 33 provinsi di Indonesia. (Pusat data dan Informasi Kementerian Kesehatan RI,2017:p.100)

\section{METODOLOGI PENELITIAN}

Penelitian ini dilakukan di Wilayah kerja Dinas Kesehatan Kota Padang, dengan desain penelitian survey deskriptif didukung dengan analisa kualitatif dan menggunakan metode wawancara mendalam (indepth interview) agar ditemukan permasalahan secara lebih terbuka. Penelitian ini bertujuan untuk mengekplorasi, mendeskripsikan, menginterprestasikan, dan mengevaluasi 
pelaksanaan manajemen laktasi pada Puskesmas Di Kota Padang.. Informan dalam penelitian ini adalah Seksi Gizi Dinas Kesehatan Kota Padang, Kepala Puskesmas, Pelaksana Pelayanan Kesehatan Ibu, Tenaga Gizi, dan pengguna pelayanan yang terdiri dari ibu hamil dan ibu menyusui.

\section{HASIL DAN PEMBAHASAN}

Tabel.

Matrik Triangulasi SDM Mengenai Manaje me n Laktasi Berdasarkan Wawancara Mendalam Dan Telaah Dokumen

\begin{tabular}{|c|c|c|c|}
\hline Topik & $\begin{array}{l}\text { Wawancara } \\
\text { mendalam }\end{array}$ & $\begin{array}{c}\text { Telaah } \\
\text { dokumen/ } \\
\text { observasi }\end{array}$ & $\begin{array}{l}\text { Analisis } \\
\text { Triangulasi }\end{array}$ \\
\hline SDM & $\begin{array}{l}\text { Tenaga kerja } \\
\text { dalam } \\
\text { pelaksanaan } \\
\text { pada } \\
\text { programini } \\
\text { sudah } \\
\text { mencukupi } \\
\text { dan terdiri } \\
\text { dari tamatan } \\
\text { DIII dan } \\
\text { DIV } \\
\text { kebidanan } \\
\text { serta dari } \\
\text { tamatan DIII } \\
\text { gizi dan } \\
\text { Sarjana } \\
\text { Kesehatan } \\
\text { Masyarakat } \\
\text { untukpoli } \\
\text { gizi }\end{array}$ & $\begin{array}{l}\text { Berdasarkan } \\
\text { observasi } \\
\text { dan } \\
\text { dokumentasi } \\
\text { pada struktur } \\
\text { pada } \\
\text { puskesmas } \\
\text { petugas } \\
\text { kesehatan } \\
\text { sudah cukup } \\
\text { dan terbagi } \\
\text { pada } \\
\text { masing- } \\
\text { masing } \\
\text { ruangandi } \\
\text { Puskesmas }\end{array}$ & $\begin{array}{l}\text { Tenaga } \\
\text { kesehatan } \\
\text { sudah } \\
\text { mencukupi } \\
\text { di masing- } \\
\text { masing } \\
\text { Puskesmas } \\
\text { tetapi } \\
\text { lulusan } \\
\text { dari DIV } \\
\text { khususnya } \\
\text { belum } \\
\text { sepenuhny } \\
\text { a tersedia } \\
\text { di } \\
\text { pelayanan } \\
\text { pada KIA } \\
\text { dan masih } \\
\text { adanya } \\
\text { tamatan } \\
\text { SKM pada } \\
\text { salah satu } \\
\text { poli }\end{array}$ \\
\hline
\end{tabular}

Berdasarkan kutipan wawancara pada tabel diatas maka kesimpulan yang dapat diambil oleh peneliti adalah informan $\mathrm{I}_{1}$ menyatakan bahwa dari data Dinas Kesehatan Kota bahwa tenaga kesehatan khususnya pada pelayanan kesehatan ibu sudah mencukupi tetapi masih ada kekurangan pada bagian staf yang belum menyelesaikan jenjang pendidikan DIV maupun S2. Kemudian dipertegas dengan pernyataan informan $I_{2}$, $\mathrm{I}_{3}$, dan $\mathrm{I}_{4}$ dimana dalam memberikan informasi sumber daya sebagian besar pelayanan kesehatan sudah merasa cukup dengan petugas yang bekerja pada masingmasing bagian tetapi masih ada beberapa yang belum sesuai seperti pada poli gizi ditempatkan tenaga kesehatan lulusan sarjana kesehatan masyarakat yang seharusnya diisi oleh lulusan tenaga gizi

Tabel.

Matrik Triangulasi KIE Berdas arkan Wawancara Mendalam Dan Telaah Dokumen

\begin{tabular}{|c|c|c|c|}
\hline Topik & $\begin{array}{l}\text { Wawancara } \\
\text { mendalam }\end{array}$ & $\begin{array}{c}\text { Telaah } \\
\text { dokumen/ } \\
\text { observasi }\end{array}$ & $\begin{array}{c}\text { Analisis } \\
\text { Triangulasi }\end{array}$ \\
\hline $\begin{array}{l}\text { KIE } \\
\text { mengenai } \\
\text { ASI }\end{array}$ & $\begin{array}{l}\text { Penyampaian KIE } \\
\text { mengenai ASI } \\
\text { dari petugas } \\
\text { kesehatan sudah } \\
\text { dilakukan melalui } \\
\text { penyuluhan } \\
\text { bersama kader, } \\
\text { KP-ASI dan } \\
\text { bekerja sama } \\
\text { dengan lintas } \\
\text { sektor maupun } \\
\text { lintas program } \\
\text { dengan } \\
\text { menggunakan } \\
\text { media }\end{array}$ & $\begin{array}{l}\text { Berdasarka } \\
\text { n observasi } \\
\text { dan } \\
\text { dokumenta } \\
\text { sipada } \\
\text { puskesmas } \\
\text { petugas } \\
\text { kesehatan } \\
\text { sudah } \\
\text { melakukan } \\
\text { penyampai } \\
\text { kan KIE } \\
\text { kepada ibu } \\
\text { tetapitidak } \\
\text { selalu }\end{array}$ & $\begin{array}{l}\text { Penyampai } \\
\text { an KIE } \\
\text { mengenai } \\
\text { ASIsudah } \\
\text { dilakukan } \\
\text { oleh } \\
\text { petugas } \\
\text { kesehatan } \\
\text { tetapi } \\
\text { belum } \\
\text { maksimal } \\
\text { kepada } \\
\text { pengguna } \\
\text { pelayanan } \\
\text { ibu hamil }\end{array}$ \\
\hline
\end{tabular}




\begin{tabular}{|l|l|l|l|}
\hline & poster/leaflet. & mengenai & maupun \\
Tetapiditemukan & ASI. & ibu \\
kesenjangan & & \\
menyusui \\
pengataan pada & & \\
pelayananan bahwa & & \\
sebagian besar ibu & & \\
mendapatkan & & \\
ibformasidari & & \\
buku dan dari & & \\
kader, KIE pun & & \\
seputarnutrisi & & \\
vitamin dan & & \\
kunjungan ulang & & \\
\hline
\end{tabular}

Berdasarkan kutipan wawancara pada tabel diatas maka kesimpulan yang dapat diambil oleh peneliti adalah informan $I_{1}$ menyatakan bahwa dari Dinas Kesehatan Kota sudah menekankan kepada masing-masing pelayanan kesehatan untuk dapat lebih proaktif dalam pelaksanaan manajemen laktasi ini. Dalam memberikan pelayanan khususnya pada penyampaian KIE mengenai ASI di Puskesmas. Kemudian dipertegas dengan pernyataan informan $I_{2}, I_{3}$, dan $I_{4}$ dimana dalam memberikan informasi mengenai ASI sebagian besar pelayanan kesehatan dengan mensosialisasikan melalui media promosi (leaflet/poster) serta berkoordinasi bersama KP-ASI, tokoh masyarakat, dan pembina wilayah pada posyandu, kelas ibu hamil maupun ibu menyusui dengan tatap muka langsung. Terdapat kesenjangan pada pengguna pelayanan menyatakan bahwa belum epenuhnya mendapatkan informasi thususnya laktasi dalam setiap pemeriksaan.

\section{KESIMPULAN DAN SARAN}

\section{A. Kesimpulan}

Berdasarkan hasil wawancara mendalam dengan partisipan terkait dengan pelaksanaan manajemen laktasi di Puskesmas, dapat disimpulkan sebagai berikut :

1. Sumber daya manusia yang sudah mencukupi dimana dalam pelayanan menggunakan instrumen seperti leaflet, brosur dan poster. Pelaksanaan ini menggunakan metode dengan berkolaborasi dengan petugas kesehatan lintas program dengan program gizi dan kesehatan ibu serta lintas sektor seperti PKK, RT, RW, kelurahan dan kecamatan dalam pembentukan KP-ASI dan pembina wilayah.

B. Saran

1. Bagi Puskesmas

a. Agar hasil penelitian ini dapat menjadi masukan dan bermanfaat meningkatkan kinerja agar pencapaian manajemen laktasi dapat tercapai sesuai target yang di harapkan, serta meningkatkan 
kualitas pelaksanaan laktasi dari waktu ke waktu.

b. Melakukan promosi kesehatan pentingnya ASI Eksklusif dikalangan masyarakat khususnya pada ibu hamil secara khusus dan masyarakat secara umum

c. Meningkatkan edukasi kepada masyarakat khususnya pada ibu menyusui dan ibu hamil agar termotivasi dalam meningkatkan capaian ASI di masyarakat.

2. Bagi Dinas Kesehatan
a. meningkatkan kualitas dan kuantitas, melalui
perkembangan-perkembangan

khusus nya untuk kesehatan ibu hamil maupun ibu menyusui serta gizi keluarga, dan selalu memfasilitasi dan membuat pertemuan bersama pembina wilayah untuk memanfaatkan fasilitas yang sudah diberikan untuk menunjang program manajemen laktasi.

b. Meningkatkan pemantauan melalui Puskesmas secara berkala.

\section{DAFTAR PUSTAKA}

Agho, Kingsley E, dkk, 2011, Determinants of exclusive breastfeeding in Nigeria, ,BMC Pregnancy and Childbirth. https://bmcpregnancy childbirth. Biomedcentral .com/ articles / 10.1186, DOI.org/10.1186/1471-239311-2_Publis Online :_January 11, 2011

Ayuningtyas, Dumilah, 2014, Kebijakan Kesehatan Prinsip dan Praktik, Jakarta : Raja Grafindo Persada

Baston, Hellen, 2011, Midwifery Essentials Postnatal, Jakarta : EGC

Depkes, 2010

Departemen Gizi dan Kesehatan Masyarakat, 2013, Gizi dan Kesehatan Masyarakat, Jakarta : Rajawali Pers

Ellya, Eva Sibagariang, 2010, Gizi dalam Kesehatan Reproduksi, Jakarta : TIM

Ermalena, 2017, Indikator Kesehatan SDG's di Indonesia, The 4th ICTOH

Hartati, Siti, 2008, Analisis determinan Pelaksanaan Manajemen laktasi Pada Pelayanan Antenatal di Puskesmas Kota Binjai tahun 2005. USU Institusional Repository, http://repository.usu.ac.id/handle/ 123456789/6804

IOS:3619.123456789-6804, Publisg Online: 14 April 2008

Hmone, Myat Pan, 2017, Factors Associated With Intention to Exclusive Breastfeed in Central Women's Hospital, Yangon, Myanmar. International Breastfeeding Journal. DOI 10.1186/s 13006-0170120-2, Published online: 06 Juli 2017

Indiarti, M.T, 2009, ASI, Susu Formula, dan Makanan Bayi, Yogyakarta : Elmatera Publishing 
Infodatin, 2014

Kemenkes RI, 2010, Buku Saku Pelayanan Kesehatan Neonatal Esensial Pedoman Teknis Pelayanan Teknis Pelayanan Kesehatan Dasar, Jakarta : Kementerian Kesehatan RI

KM, Edmond, et all, (2006), Delayed Breastfeeding Initiation Increases Risk of Neonatal Mortality, https://www.ncbi.nlm.nih.gov /pubmed/ 16510618 DOI:10.1542/peds.2005-1496, Publish Online: March 2006

Krisnamurti, dkk, 2013, Evaluasi Pelaksanaan 10 Langkah Menyusu Keberhasilan Menyusui (Studi pada Bidan di Rumah Sakit Angkatan Laut dr. Ramelan Surabaya.Jurnal Manajemen Kesehatan Indonesia, Volume 01 No.03, Publish Desember 2013

Marie, Naomy Tando, 2016, Asuhan Kebidanan Neonatus, Bayi, dan Anak Balita, Jakarta : EGC

Marmi, dkk, 2015, Asuhan Neonatus, Bayi, Balita, dan Anak Prasekolah, Yogyakarta : Pustaka Belajar

Maryunani, Anik, 2012, Inisiasi Menyusu Dini Asi Eksklusif dan Manajemen Laktasi, Jakarta : TIM

Manning, Bowden, 2011, Promosi Kesehatan Dalam Kebidanan, Jakarta : EGC

Monika, F.B, 2014, Buku Pintar ASI dan Menyusui, Jakarta : Noura Books

Murray, Michelle L, 2013, Persalinan \& Melahirkan Praktik Berbasis Bukti, Jakarta : EGC
Ogbo, Felix A, dkk, 2017, Prevalence and determinants of cessation of exclusive breastfeeding in the early postnatal period in Sydney, Australia, International Breastfeeding Journal, DOI 10.1186/s 13006-017-0110-4, Published online:08 April 2017

Pollard, Maria, 2015, ASI Asuhan Berbasis Bukti, Jakarta : EGC

Pusat Data dan Informasi Kementerian Kesehatan RI, 2017

Purwoastuti, Endang, 2015, Ilmu Kesehatan Masyarakat Dalam Kebidanan Konsep, Teori dan Aplikasi, Yogyakarta : Pustaka Baru

Profil Kesehatan Indonesia, 2014

Profil Kesehatan Indonesia, 2015

Profil Kesehatan Provinsi Sumatera barat, 2014

Profil Kesehatan Kota Padang, 2016

Reddy, Surender,dkk, 2014, Determinants of Exclusive Breastfeeding Practice Among Mother of Children Under Two Years Old In Dilla Zuria District, Gedeo Zone, Ethiopia, Journal of Pregnancy and Child Health. Department of Public Health College of Medicine and Health Science Wollo University Ethiopia. Department of Public Health Dilla University College of Health Sciences and Medicine Ethiopia. ISSN : 2376-127X. Publish Online: February 26, 2016

Saryono, dkk, 2013, Metodologi Penelitian Kualitatif dan Kuantitatif dalam Bidang Kesehatan, Yogyakarta : Numed 
World Health Organization, 2013, WHO Recommendations on Postnatal Care of The Mother and Newborn
Yuli Astutik, Reni, 2014, Payudara dan Laktasi, Jakarta : Salemba Medika 